\title{
ESTUDOS BIOGEOQUÍMICOS NO COMPLEXO GRANITICO LAVRAS, LAVRAS DO SUL, RS
}

\author{
MARIA DO CARMO LIMA E CUNHA*
}

\begin{abstract}
BIOGEOCHEMICAL STUDIES IN THE LAVRAS GRANITIC COMPLEX, LAVRAS DO SUL, RS. Biogeochemical investigations in the Lavras Granitic Complex, Lavras do Sul (RS), suggest that Schinus lentiscifolius is an indicator of polymetallic sulphides associated with gold, occurring in the granitic rocks which characterize this complex. The geobotanical and biogeochemical studies reported in this work confirm that this species can be considered suitable to biogeochemical prospecting in the mineralized district of the Sul-rio-grandense Shield.
\end{abstract}

\begin{abstract}
RESUMO ESTUDOS BIOGEOQUÍMICOS NO COMPLEXO GRANÍTICO LAVRAS, LAVRAS DO SUL, RS. Pesquisas biogeoquímicas feitas no Complexo Granítico Lavras, Lavras do Sul, RS, sugerem que a espécie Schinus lentiscifolius é indicadora dos sulfetos polimetálicos, associados à presença de ouro, ocorrentes nas rochas graníticas que caracterizam este complexo. Os estudos geobotânicos e biogeoquímicos apresentados neste trabalho confirmam que a espécie pode ser considerada apropriada para a prospecção biogeoquímica no distrito mineralizado do Escudo Sul-rio-grandense.
\end{abstract}

INTRODUÇÃO Este trabalho trata do reconhecimento biogeoquímico das anomalias geoquímicas com vistas à prospeç̧ão mineral, utilizando-se a espécie Schinus lentiscifolius (aroeirinha), de larga ocorrência sobre os solos que recobrem o Complexo Granítico Lavras, Lavras do Sul (RS) (Fig. 1).

Neste sentido, foi feita uma amostragem dos vegetais que ocorrem sobre os três tipos litológicos que compõem este complexo, cujas mineralizações se caracterizam por veios de quartzo contento sulfetos de $\mathrm{Cu}, \mathrm{Pb}, \mathrm{Zn}$, além de ouro e molibdenita.

O objetivo do presente estudo é constatar se as cinzas da espécie $S$. lentiscifolius revelam concentraçőes anồmalas de elementos metálicos de modo similar áos exemplares da mesma espécies analisados para as regiōes de Cerro dos Martins e Mina do Seival, município de Caçapava do Sul e Bela Vista, munícipio de Bagé (RS) (Lima e Cunha 1980, 1982).

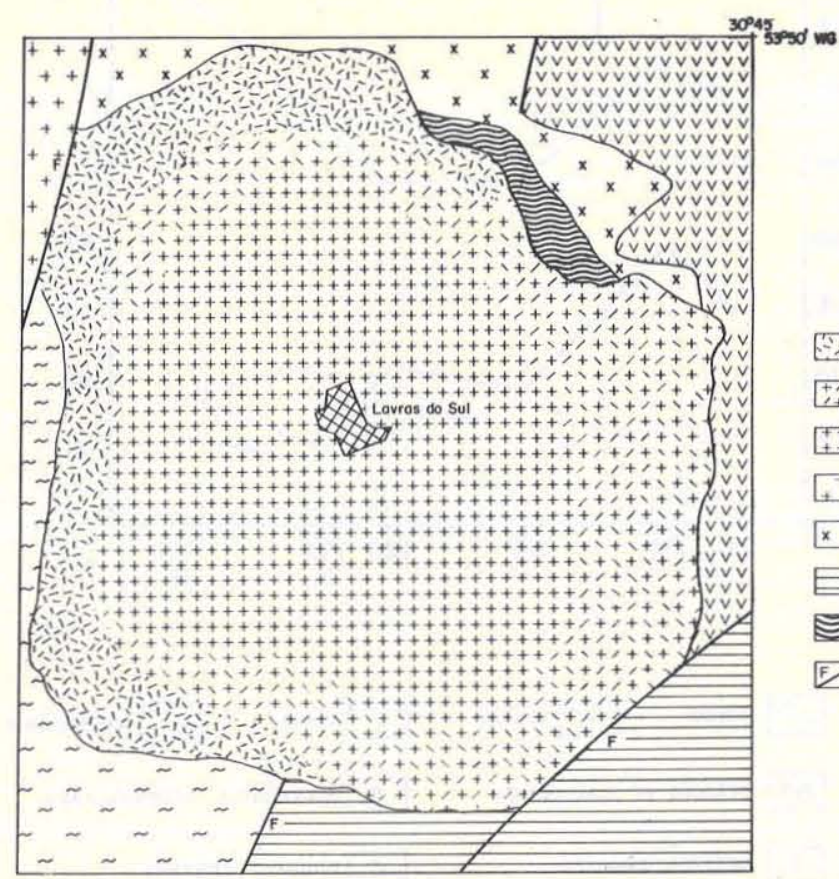

GEOLOGIA A geologia da área, representada esquematicamente na Figura 1, é composta por um conjunto de rochas graníticas que, segundo Nardi (1984), se distinguem textural e petrograficamente em três tipos: a. um corpo central com textura porfirítica, sem evidências de deformações e com um sistema de fraturas de direções dominantes NE e NW; neste último, ocorrem veios de quartzo mineralizados com sulfetos (pirita, calcopirita, galena, esfalerita e molibdenita) associados à presença de ouro; b. um corpo transicional, com textura porfirítica gradando para eqüigranular, que praticamente circunda o corpo central; e c. um terceiro tipo, de borda, constituído por um pertita granito, leucocrático, eqüigranular, contendo mineralizações de pirita e ouro em zonas brechadas de direção $\mathrm{E}-\mathrm{W}$.

Os processos de alteração hidrotermal que afetaram o Complexo Granítico Lavras, em seu estádio mais avançado

Figura 1-Mapa geológico do Complexo Granítico Lavras (Nardi 1984) e localização geográfica da área de estudo

\footnotetext{
* Departamento de Geologia, Instituto de Geociências, Universidade Federal do Rio Grande do Sul. Avenida Bento Gonçalves, 9500, Campus do Vale, CEP 91500, Porto Alegre, RS
} 
(sericitização), dão às rochas uma coloração esverdeada que se torna mais intensa quando em proximidade dos veios de quartzo, enriquecidos em sulfetos e ouro, que cortam os três tipos litológicos.

VEGETAÇÃO O arbusto dominante na região estudada é uma espécie considerada adequada à prospecção biogeoquímica por concentrar de modo significativo alguns elementos metálicos ocorrentes nas regiōes mineralizadas do Escudo Sul-rio-grandense (Lima e Cunha 1982, Porto 1981), daí a seleção de $S$. lentiscifolius como a espécie mais representativa em termos de amostragem na área trabalhada.

O predomínio de $S$. lentiscifolius lhe confere um caráter ecotipicamente distinto, condicionado edaficamente pela influência das mineralizaçóes e cujo modo de ocorrência, em termos de distribuição e densidade, Rambo (1956) qualifica como "Matas de Parque" e Porto (op. cit.) classifica como "Savana de Arbustos".

O comportamento arbustivo da aroeirinha e sua predominância sobre as demais espécies, na área do Complexo Granítico Lavras, em muito se igualam às observaçōes feitas por Lima e Cunha (1982) e Porto (op. cit.) para outras regioes ricas em sulfetos do Escudo Sul-rio-grandense, onde a mesma se apresenta como uma pequena árvore de copa arredondada e muito ramificada, com tendência ao nanismo, sendo esta característica comum as especies que se desenvolvem sobre solos cupríferos (Brooks 1983). Quando sobre o Complexo Granítico Lavras se observou ainda que a espécie apresenta outras alteraçōes morfologicas como tamanho (mais reduzido) e cor (verde pálida) dos folíolos, e ramos secundários mais finos, dando à planta um aspecto prostado, principalmente onde o teor de zinco na espécie é maior (minas Rezende e Săo José).

AMOSTRAGEM E MÉTODOS ANALÍtICOS Os vegetais (79 amostras) foram coletados tanto sobre as áreas mineralizadas (veios de quartzo com sulfetos e zonas hidroter. malmente alteradas com sulfetos disseminados), como em áreas supostamente estéreis, nos três diferentes granitos que caracterizam o complexo.

Aproximadamente $50 \%$ das amostras foram coletadas em estações próximas ou coincidentes àquelas de amostragem de rochas (Nardi 1984). Cerca de 20 amostras foram coletadas em algumas das minas existentes na regiăo, quais sejam; Bloco Butiá, Olaria, Virgínia, São José, Santo Expedito, Rezende, Pitangueira e Dourada. As demais coletas foram feitas preferencialmente ao longo de perfis de direção NE-SW e NW-SE (Fig. 2).

O material selecionado para análise (folhas) foi lavado em água deionizada, secado a $1000^{\circ} \mathrm{C}$ e calcinado a $450-500^{\circ} \mathrm{C}$ por seis horas. Posteriormente, as cinzas foram dissolvidas em $\mathrm{HCl}(3 \mathrm{~N})$ e as soluções analisadas por espectrofotometria de absorção atômica, visando a determinação de $\mathrm{Cu}, \mathrm{Pb}, \mathrm{Zn}$ (78 amostras) e $\mathrm{Rb}$ (38 amostras), além de $\mathrm{Ca}, \mathrm{Mg}, \mathrm{Fe}, \mathrm{K}, \mathrm{Mn}$ e $\mathrm{Na}$ (38 amostras). O Mo (78), dadas as baixas concentrações não detectáveis por absorção atômica, foi analisado por espectrografia optica de emissão. Todas as determinações foram feitas no Laboratório de Geoquímica da UFRGS.

Para se avaliar a inter-relação dos elementos maiores e alguns menores com os elementos -traços na planta, em termos de competição e/ou relação iônica nos processos físiologicos, selecionou-se apenas parte das amostras para este fim.

Os teores dos elementos analisados são expressos em peso seco, seguindo as recomendaçôes de Brooks (1983), por refletir de modo mais consistente a real situação da planta quando matéria viva.

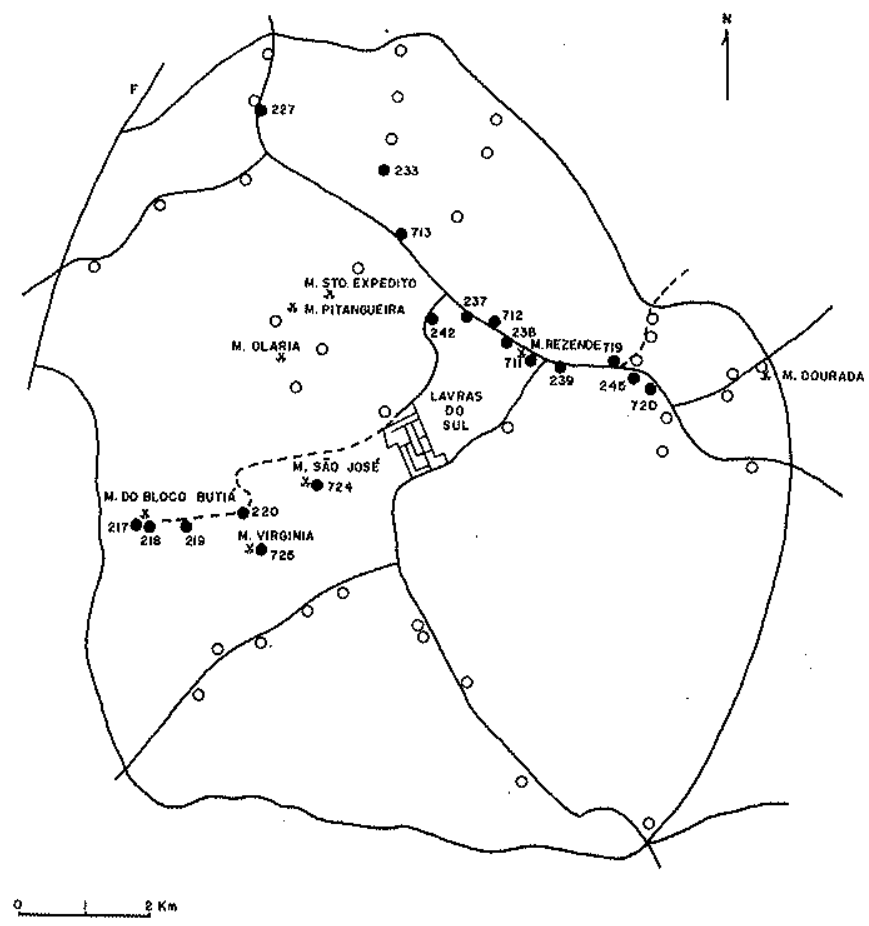

Figura 2 - Mapa de localização dos perfis biogeoquímicos $e$ demais estaçôes de amostragem

3, com direção W-E, feito sobre uma área com mineralização conhecida e partindo do pertita granito para o granito central, revela que o padrão de distribuição do zinco está relacionado à
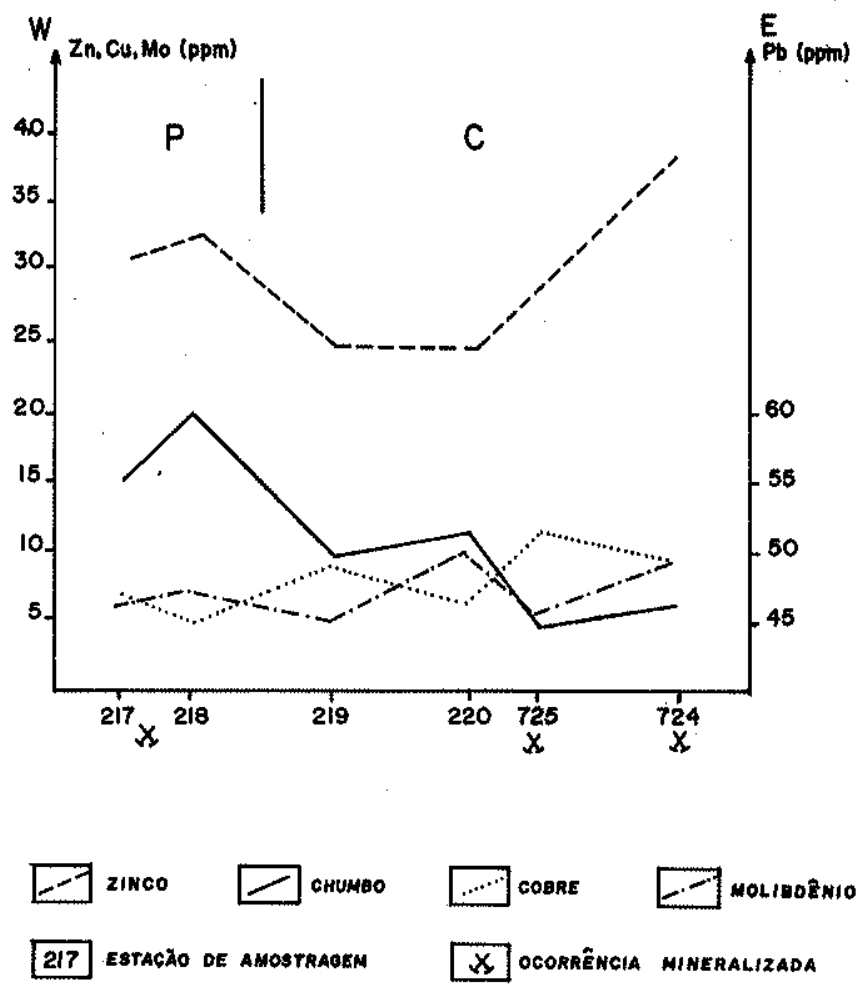

P PERTITA ORANITO

C ORAMITO Gentral.

Figura 3 - Perfil biogeoquímico. Variação dos teores de $\mathrm{Cu}$, $\mathrm{Zn}, \mathrm{Pb}$ e Mo em S. lentiscifolius em relação às litologias do Complexo Grantitico Lavras e mineralizaçóes aflorantes. Direção W-E. Nota: Os valores de Mo e Pb estão expressos em peso de cinzas 
área mineralizada, com um contraste maior quando sobre o granito central.

$\mathrm{O} \mathrm{Mo}$ e o $\mathrm{Pb}$, semelhantes entre si em sua distribuição, somente refletem as anomalias quando a concentração do cobre decresce. Neste exemplo, percebe-se ainda o nítido antagonismo existente entre o $\mathrm{Cu}$ e o Mo, evidenciando os efeitos competitivos entre seus íons no processo de absorção.

Na Figura 4, o perfil tem uma direção NW-SE, também feito sobre ocorrências conhecidas e abrange os três tipos litológicos que compõem o Complexo Granítico Lavras. Neste caso, o comportamento biogeoquímico dos elementos é semelhanté ao do exemplo acima. O zinco se mostra como o melhor indicador da mineralização, com um contraste maior quando sobre o grănito central; o $\mathrm{Pb}$ e o Mo revelam um mesmo padrão de distribuição e também refletem as ocorrências, embora de modo menos intenso que o zinco. Percebe-se ainda a ação antagônica entre o $\mathrm{Mo}$ e o $\mathrm{Cu}$ e o controle que a planta exerce no processo de absorção deste último, indicando que tal fenômeno é regido por sistemas diferentes daqueles que comandam a absorção do zinco. Isto porque, geralmente, a quantidade de zinco existente na planta é proporcional à sua quantidade no solo, não existindo, pelo menos a nível de raiz, um mecanismo de exclusão a exemplo do que acontece com o cobre. Para este elemento, o processo de absorção é marcadamente controlado pela planta por mecanismos tanto externos (a nível de raiz) como internos (Antonovics et al. 1971).

Quanto mais eletronegativo for um elemento metálico, maior será seu grau de toxicidade para a planta (Brooks 1983). A afirmativa deste autor se baseia no fato de que elementos como $\mathrm{Cu}, \mathrm{Hg}$ e $\mathrm{Ag}$, entre outros, terem grande afinidade com o grupo das sulfidrilas, que é reativo com muitas enzimas, ficando estas incapacitadas em suas funções e como conseqüências ocorre a toxicidade.

Deste modo, por ter o cobre um papel importante na atividade enzimática, sua absorção é largamente dosada pela planta, o que não aćntece com o zinco, cuja eletronegatividade,
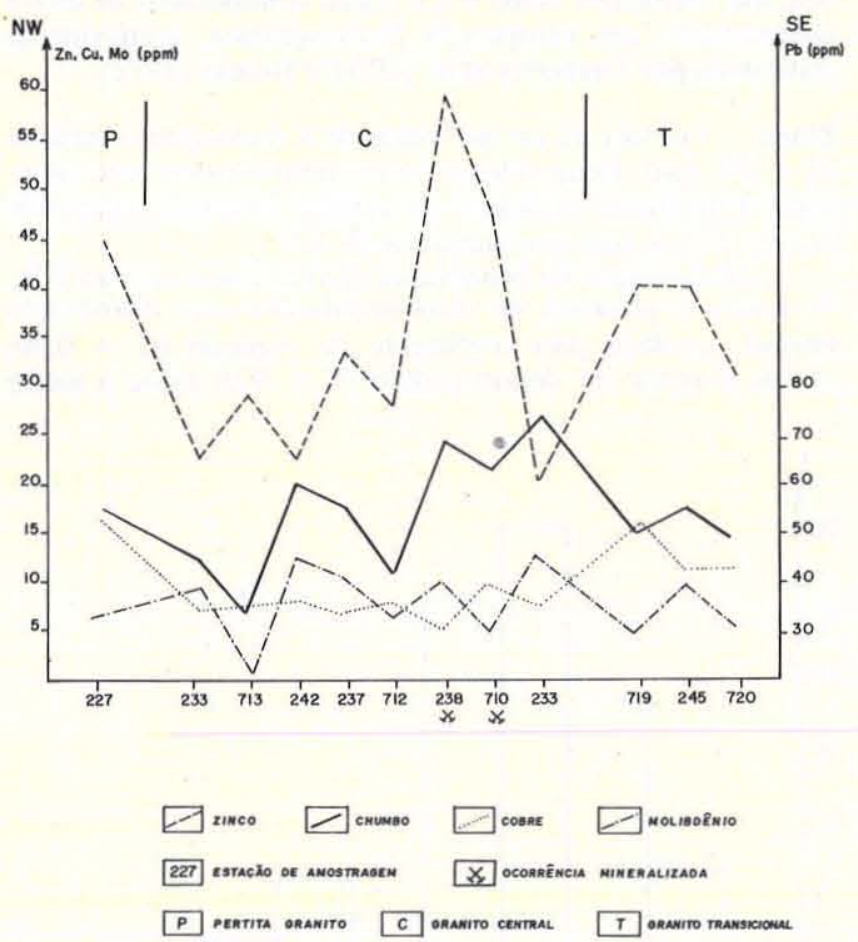

Figura 4 - Perfil biogeoquímico. Variação dos' teores de $\mathrm{Cu}$, $\mathrm{Zn}, \mathrm{Pb}$ e $\mathrm{Mo}$ em $\mathrm{S}$. lentiscifolius em relação às litologias do Complexo Granítico Lavras e mineralizações aflorantes. Direção $N W-S E$. Nota: $O s$ valores de Mo e Pb estão expressos em peso de cinzas bem menor, o torna menos tóxico e conseqüentemente mais livremente absorvido. É por este motivo que o zinco, se disponível à planta, a despeito de sua essencialidade, é concentrado nesta proporcionalmente aos teores existentes no solo.

Observando-se o comportamento dos quatro elementos considerados nas figuras 3 e 4 , nota-se que a planta, ao absorver mais um elemento, bloqueia outro quando a disponibilidade deste é maior que o seu limite de tolerância. Esta constatação permite concluir que a espécie $S$. lentiscifolius tem um caráter de multitolerância e ao mesmo tempo indicador das mineralizaçőes conhecidas na área do Complexo Granítico Lavras.

TRATAMENTO ESTATÍSTICO DOS DADOS Dados estatísticos dos 11 elementos analisados nas cinzas das folhas de $S$. lentiscifolius são apresentados na Tabela 1 . Os elementos metálicos foram analisados com o objetivo de se detectar os possíveis indicadores biogeoquímicos das ocorrências polimetálicas do Complexo Granítico Lavras. Juntamente com estes, alguns elementos maiores foram considerados visando-se a interação destes entre si e com os elementos-traço. Já a análise do rubídio foi feita com o propósito de se avaliar a precisão analítica do método empregado neste trabalho e comparar sua concentração média, nesta espécie, com a existente na literatura.

Tabela 1 - Parâmetros estatísticos dos elementos analisados nas cinzas de folhas de $\mathrm{S}$. lentiscifolius (peso seco)

\begin{tabular}{|c|c|c|c|c|c|}
\hline & $n$ & $\overline{\mathrm{x}}$ & $S$ & $\mathrm{C}$ & Distribuição \\
\hline $\mathrm{Cu}$ & (78) & 10,00 & 2,60 & 0,29 & $5,00-37,00 \mathrm{ppm}$ \\
\hline $\mathrm{Zn}$ & (78) & 32,00 & 10,00 & 0,30 & $13,00-177,00 \mathrm{ppm}$ \\
\hline Mo & (71) & 0,60 & 0,25 & 0,48 & $0,07-1,40 \mathrm{ppm}$ \\
\hline $\mathrm{Pb}$ & (78) & 3,50 & 0,70 & 0,20 & $2,00-8,00 \mathrm{ppm}$ \\
\hline $\mathrm{Rb}$ & (78) & 27,00 & 5,60 & 0,20 & $18,00-40,00 \mathrm{ppm}$ \\
\hline $\mathrm{Fe}$ & (38) & 175,00 & 89,00 & 0,50 & $70,00-400,00 \mathrm{ppm}$ \\
\hline Mn & (37) & 185,00 & 90,00 & 0,48 & $60,00-600,00 \mathrm{ppm}$ \\
\hline $\mathrm{Ca}$ & (38) & 1,60 & 0,30 & 0,18 & $1,00-2,00 \%$ \\
\hline $\mathrm{Mg}$ & (38) & 0,20 & 0,04 & 0,20 & $0,06-0,30 \%$ \\
\hline $\mathrm{Na}$ & (34) & 0,03 & 0,01 & 0,33 & $0,01-0,10 \%$ \\
\hline K & (38) & 1,33 & 0,33 & 0.24 & $1,00-2,40 \%$ \\
\hline
\end{tabular}

As médias obtidas para $\mathrm{Ca}, \mathrm{Mg}, \mathrm{K}$ e $\mathrm{Na}$ estão dentro daqueles valores registrados por Connor \& Schacklette (1975) para as plantas nativas. O rubídio, embora tenha em termos petrogenéticos um comportamento relacionado com as variaçōes litológicas e composicionais do Complexo Granítico Lavras, biogeoquimicamente não se revelou significativo. Sua concentração média é condizente com a de Kabata-Pendias \& Pendias (1984) para as plantas superiores (20 a $70 \mathrm{ppm}$ ). Contudo, se tomados os valores isoladamente nos três tipos de granito, percebe-se que a média dos teores na planta aumenta do granito central para o pertita granito, a exemplo do que ocorre nas rochas deste complexo, segundo Nardi (1984).

Para Fe e Mn, as médias obtidas por Connor \& Schacklette (op. cit.) em plantas nativas são de 90 e 60 ppm (peso seco), respectivamente. Pela tabela 1 , observa-se que o $\mathrm{Mn}$ em $S$. lentiscifolius tem um valor médio três vezes acima do apresentado por esses autores e o Fe, o dobro do valor médio. Esta maior disponibilidade do $\mathrm{Mn}$, e secundariamente do $\mathrm{Fe}$, para a espécie considerada, pode ser decorrente da alteração de minerais ferromagnesianos que acompanham as mineralizaçōes sulfetadas do Complexo Granítico Lavras.

Para o $\mathrm{Cu}$ e o $\mathrm{Zn}$, considerando-se os teores registrados na literatura para os vegetais que ocorrem sobre solos não anômalos (Tab. 2), observa-se que em $S$. lentiscifolius, na área 
estudada, a concentração média desses elementos é significativa. Já os valores médios de $\mathrm{Pb}$ e $\mathrm{Mo}$, da tabela 1 , quando confrontados com os da tabela 2 , em termos estatísticos, são inexpressivos.

Tabela 2 - Concentração média aproximada de $\mathrm{Cu}, \mathrm{Pb}, \mathrm{Zn}$ e Mo em plantas ocorrentes sobre solos não anômalos segundo diferentes autores (ppm em peso seco)

\begin{tabular}{llllc}
\hline Autores Elemento & $\mathrm{Cu}$ & $\mathrm{Zn}$ & $\mathrm{Pb}$ & Mo \\
\hline Chukhrov et al. (1979) & 4,00 & 10,00 & - & - \\
Connor \& Shacklette (1975) & 6,00 & 28,00 & 4,00 & 0,35 \\
Beus \& Grigorian (1977) & 1,30 & 25,00 & 2,50 & 0,50 \\
Kabata-Pendias \& Pendias (1984) & 5,0 & 30,00 & 2,00 & 0,60 \\
Brooks (1986) - inf. verbal & 5,50 & 25,00 & - & - \\
& $\mathbf{4 , 3 0}$ & 24,00 & $\mathbf{3 , 0 0}$ & 0,50 \\
\hline
\end{tabular}

A seguir são apresentados e discutidos os padrōes de distribuição dos elementos empregados na prospecção biogeoquímica na área estudada, cujas anomalias, detectadas a partir do tratamento estatístico, estâo representadas na Figura 13.

Cobre A concentração de Cu na espécie estudada varia de 5 a $37 \mathrm{ppm}$. Os dados foram agrupados em sete intervalos de classe, excluídos os valores extremos, com uma amplitude de 1,8 (Garret 1984). O histograma de freqüência simples (Fig. 5) apresenta um padrão de distribuição assimétrico, levemente negativo, muito embora o coeficiente de variaçäo $(C=0,29)$, obtido do desvio-padrão sobre a média aritmética $(\bar{x}=10)$, mostre uma distribuição do tipo normal.

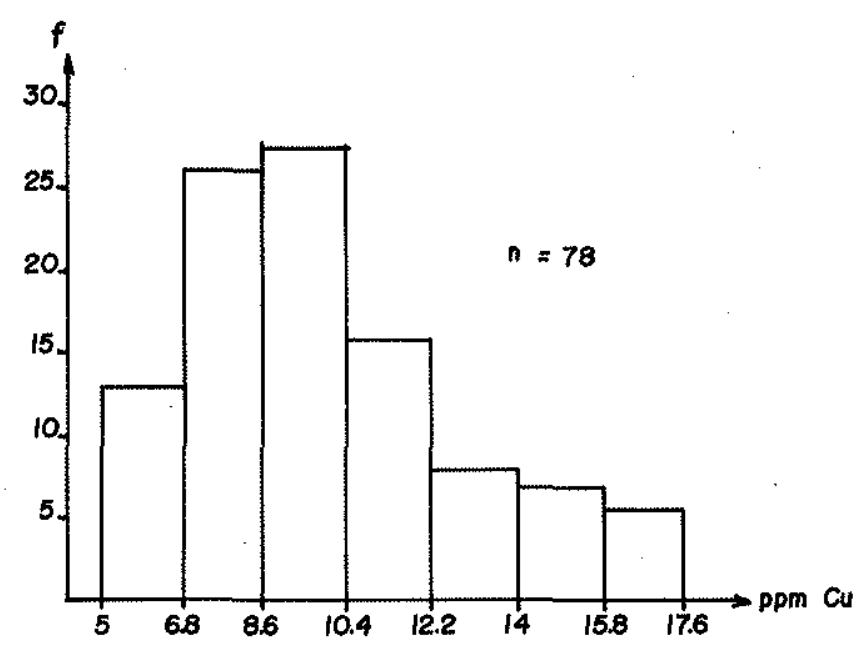

Figura 5-Histograma de freqüência simples dos teores de Cu em amostras de S. lentiscifolius da area do Complexo Grantitco Lavras (intervalos aritméticos)

Em casos como este é aconselhável utilizar-se o teste de assimetria $(g 1)$, que para a distribuição biogeoquímica do $\mathrm{Cu}$ revelou um coeficiente de 0,55 (valor crítico para 78 amostras $=0,42$ ), comprovando sua lognormalidade.

Como conseqüência, a construção da curva de freqüência acumulada (Fig. 6) foi feita em papel de probabilidades logarítmica, adotando-se os critérios de Lepeltier (1969) e Sinclair (1976), para a determinação dos valores de background e limiar. No entanto, considerando-se que os valores médios de
Cu em $S$. lentiscifolius, na área estudada, são relativamente altos (comparar as tabelas 1 e 2 ), o percentil 34 da curva de freqüência acumulada (equivalente a $\bar{x}+0,5 S$ ) foi escolhido para a determinação das anomalias de segunda ordem $(>12$ ppm) e o percentil 16 para as anomalias de primeira ordem (> $14 \mathrm{ppm})$.

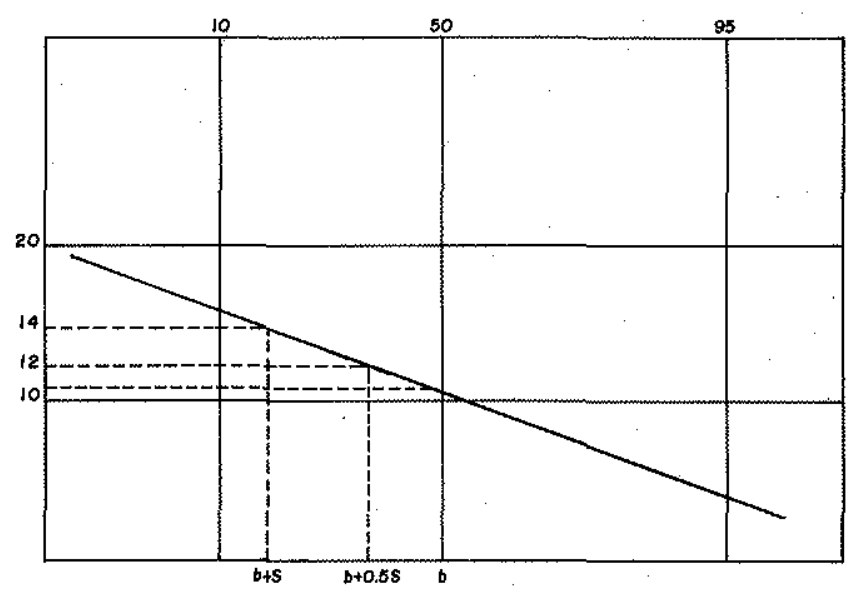

Figura 6 - Curva de freqüência acumulada dos teores de Cu em amostras de S. lentiscifolius da area do Complexo Grantico Lavras (intervalos aritméticos)

Das amostras biogeoquimicamente anômalas (16), somente $18,7 \%$ estão sobre áreas com ocorrências conhecidas, o que leva a se concluir que o $\mathrm{Cu}$, por sua essencialidade à planta, faz com que esta desenvolva uma capacidade de regular fortemente sua absorção, para compensar as concentrações do substrato acima ou abaixo de seu grau de exigência. Isso faz com que elementos como o $\mathrm{Cu}$ sejam considerados de difícil interpretação em prospecção biogeoquímica, conforme já constatado por Timperley et al. (1970) e Brooks (1972).

Zinco $\mathrm{O}$ teor de $\mathrm{Zn}$ nas folhas de $S$. lentiscifolius varia de 13 a $177 \mathrm{ppm}$. Esses valores foram agrupados em sete intervalos aritméticos, excluídos os valores extremos, conforme Garret (1984), com uma amplitude de 6,7.

A configuração do histograma de freqüência simples (Fig. 7) revela a presença de duas populaçōes com distribuição normal, atestada pelo coeficiente de variação $(C=0,30)$ obtido a partir do desvio-padrão $(S=9,9)$ sobre a média

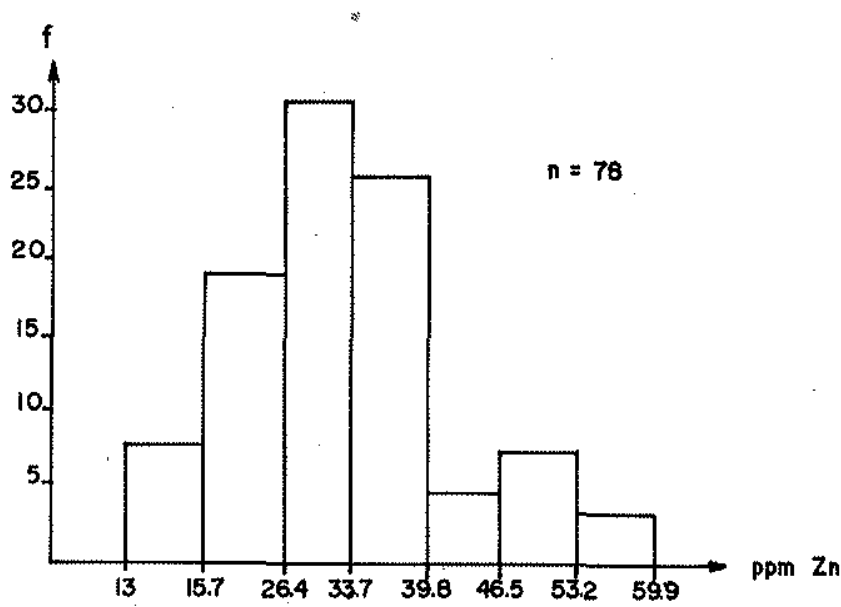

Figura 7 - Histograma de freqüência simples dos teores de $\mathrm{Zn}$ em amostras de S. lentiscifolius da área do Complexo Grantico Lavras (intervalos aritméticos) 
aritmética $(\bar{x}=32)$. A quebra na curva de freqüência acumulada, feita em papel de probabilidade aritmética (Fig. 8), evidencia claramente a presença de duas populaçöes, normalmente distribuídas, e uma terceira resultante de mistura das duas primeiras.

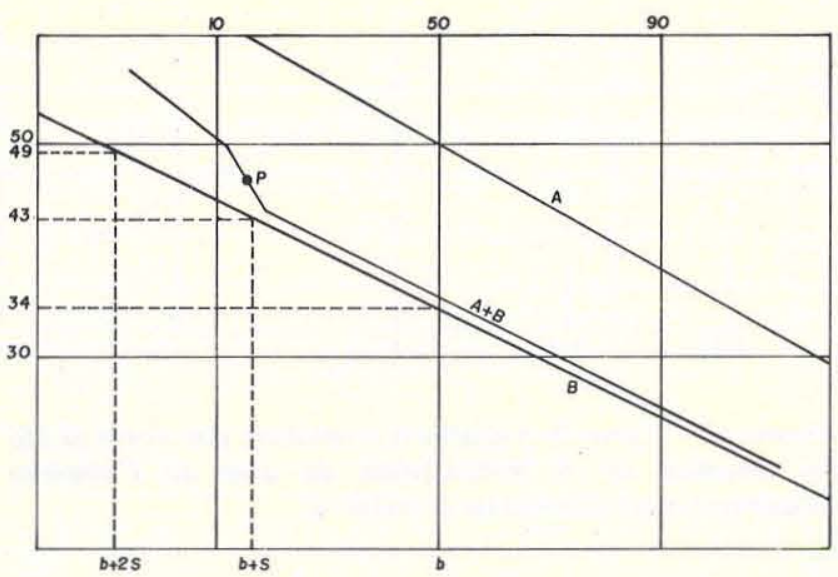

Figura 8 - Curva de freqüência acumulada dos teores Zn em amostras de $\mathrm{S}$. lentiscifolius da área do Complexo Granítico Lavras (intervalos aritméticos). Obs.: População total $(A+B)$ dividida em população de background $(B)$ e população anômala (A), segundo Sinclair (1976). $\mathrm{p}=$ ponto de inflexão

A separação dessas populações foi feita de acordo com os critérios de Sinclair (1976). Como resultado, dois limiares podem ser estabelecidos: o primeiro obtido no percentil 99 da população $\mathrm{A}(<28 \mathrm{ppm})$ e o segundo no percentil $1 \mathrm{da}$ população B (> $54 \mathrm{ppm})$. Portanto, do total de amostras (78), $3,8 \%$ (três amostras) pertencem à população anômala, ou seja, maior que $54 \mathrm{ppm}$, e $30,7 \%$ (24 amostras) pertencem à população de background ( $<28 \mathrm{ppm})$.

Da população de mistura $65,6 \%$, ou seja, 51 amostras, $14,7 \%$ (sete amostras) devem pertencer à população de background.

Deste modo, as anomalias biogeoquímicas de $\mathrm{Zn}$ podem ser assim estabelecidas: o percentil 50 da população $B$ representa os valores de background $(=34 \mathrm{ppm})$; o percentil 16 , as anomalias de segunda ordem ( $>43 \mathrm{ppm})$; e o percentil 2,5, as anomalias de primeira ordem ( $>49 \mathrm{ppm})$. Do total de amostras anômalas (13), 60\% estão dentro de áreas com mineralização conhecida. Estes fato revela que a espécie é uma indicadora significativa das anomalias de $\mathrm{Zn}$ no Complexo Granítico Lavras.

Em termos geoquímicos, a presença de duas populações de $\mathrm{Zn}$ associada a uma terceira, de mistura, pode ser decorrente de diferenciação litológica existente no Complexo Granítico Lavras. Nardi (1984), referindo-se à distribuição dos elementos-traço neste complexo, constata que o teor de $\mathrm{Zn}$ aumenta da zona central para o granito de borda (pertita), sendo este último mais enriquecido em $\mathrm{Zn}$, como os demais granitos alcalinos. Para este autor, as rochas da zona central não pertencem à mesma série magmática, sendo o granito transicional considerado um corpo híbrido com feiçōes geoquímicas intermediárias entre os dois tipos principais. A concentração de $\mathrm{Zn}$ nas cinzas de $\mathrm{S}$. lentiscifolius também retrata esta diferenciação, com teores médios de $30 \mathrm{ppm}$ nas amostras do corpo central; de $34 \mathrm{ppm}$ nas pertencentes ao granito transicional; e de $36 \mathrm{ppm}$ nas coletadas no pertita granito.

Chumbo Os valores de $\mathrm{Pb}$ nas cinzas das folhas de $S$. lentiscifolius variam de 2 a 8 ppm. Estes valores foram agrupados em oito intervalos aritméticos, com uma amplitude de 0,4 , excluídos os valores extremos. A escolha do número intervalos, para a construção do histograma, foi feita a partir da sugestâo de Garret (1984). Pelo histograma (Fig. 9), percebe-se a presença de uma população normal unimodal. O coeficiente de variação $(C=0,20)$, obtido do desvio-padrão $(0,70)$ sobre a média aritmética $(\bar{x}=3,5)$, reforça este tipo de

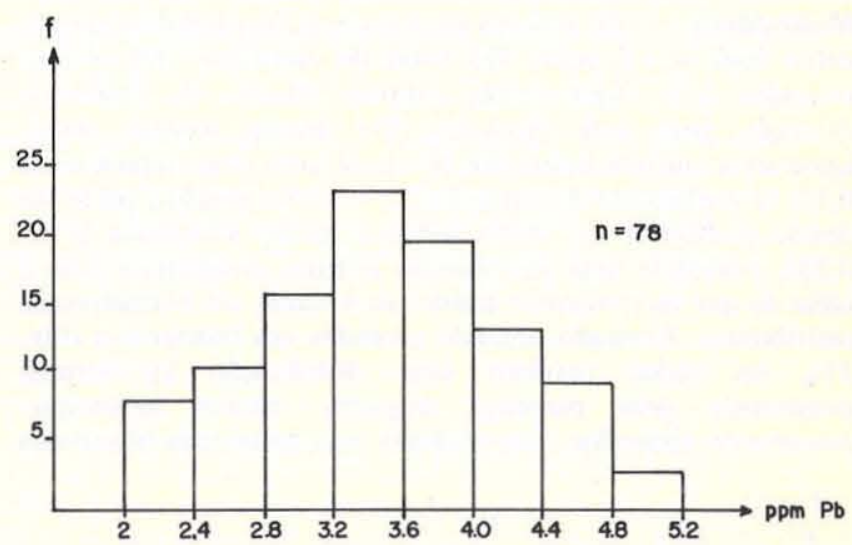

Figura 9 - Histograma de freqüência simples dos teores $\mathrm{Pb}$ em amostras de S. lentiscifolius da área do Complexo Granítico Lavras (intervalos aritméticos).

distribuição. Neste caso, a curva de freqüência acumulada (Fig. 10) foi feita em papel de probabilidade aritmética e a seleção dos critérios para a escolha dos valores de background e do limiar foi feito conforme Lepeltier (1969), em que a mediana revelou um valor de $3,7 \mathrm{ppm}$ e os percentis 16 e 2,5 indicam as anomalias de segunda ( $>4,5 \mathrm{ppm})$ e primeira ordens ( $>5 \mathrm{ppm})$, respectivamente.

Vale ressaltar que, quando em presença de uma populaçảo normalmente distribuída, o emprego de critérios estatísticos mais sofisticados, como os de Sinclair $(1974,1976)$ ou de Lepeltier (op. cit.), é válido por fornecer um embasamento mais significativo quando se trabalha com dados agrupados.

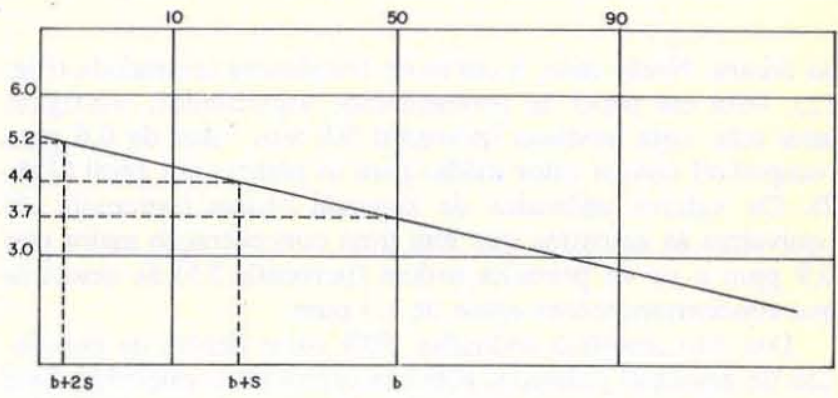

Figura 10 - Curva de freqüência acumulada dos teores $\mathrm{Pb}$ em amostras de S. lentiscifolius da área do Complexo Granítico Lavras (intervalos aritméticos)

Contudo, em casos como o aqui apresentado, o tratamento por meio de técnicas mais simples (e.g. Hawkes \& Webb 1962), mostra que os resultados, quando confrontados (ver na tabela 3), não diferem significativamente.

Do total de amostras anômalas (10), 30\% coincidem geograficamente com áreas com mineralização conhecida. Como se percebe, o $\mathrm{Pb}$, comparativamente ao $\mathrm{Zn}$, não é um indicador biogeoquímico significativo das anomalias geoquímicas. 
Tabela 3 - Seleção de background e limiar para chumbo em folhas de S. lentiscifolius (ppm em peso seco)

$\begin{array}{ll}\text { Hawkes \& Weeb (1962) } & \text { Lepeltier (1969) } \\ \bar{x}=3,5 & \text { Mediana }=3,7 \\ \bar{x}+\mathrm{S}=4,2 & \text { Percentil } 16=4,4 \\ \bar{x}+2 \mathrm{~S}=4,9 & \text { Percentil } 2,5=5,2\end{array}$

Molibdênio Os valores de Mo em $S$. lentiscifolius variam entre 0,07 e $1,4 \mathrm{ppm}$. Do total de amostras (78), foram retiradas sete cujos teores estavam abaixo do limite de detecção para este elemento. Os demais valores foram agrupados em sete intervalos de classe com uma amplitude de 0,17 . O coeficiente de variação $(C=0,48)$, obtido a partir do desvio-padrão $(S=0,25)$ sobre a média aritmética $(\bar{x}=$ $0,58)$, evidencia uma distribuição normal, compatível com a idéia de que os elementos essenciais à planta são normalmente distribuídos. Contudo, quando plotados em histograma (Fig. 11), os dados revelam uma distribuição log-normal, ocasionada pela presença daqueles valores biogeoquimicamente anômalos, responsáveis pela assimetria observada

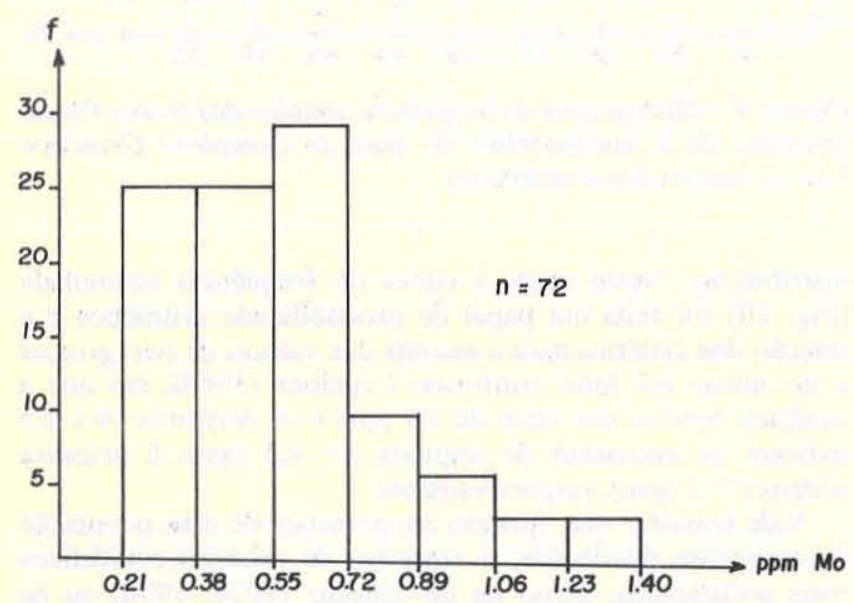

Figura 11 - Histograma de freqüencia simples dos teores de Mo em amostras de S. lentiscifolius da área do Complexo Granítico Lavras (intervalos aritméticos)

na figura. Neste caso, a curva de freqüência acumulada (Fig. 12), feita em papel de probabilidade logarítimica, configura uma reta, cuja mediana (percentil 50 ) tem valor de $0,6 \mathrm{ppm}$ compatível com o valor médio para as plantas em geral (Tab. 2). Os valores anômalos de segunda ordem (percentil 16) equivalem às amostras que têm uma concentração maior que $0,9 \mathrm{ppm}$ e os de primeira ordem (percentil 2,5) às amostras que concentram teores acima de $1,3 \mathrm{ppm}$.

Das oito amostras anômalas, $50 \%$ caem dentro da população de amostras coletadas sobre ocorrências conhecidas. Este fato revela que, a exemplo do $\mathrm{Zn}$, existe uma maior disponibilidade de Mo para a planta, na área estudada, principalmente quando sobre o granito central, no qual a molibdenita ocorre com maior freqüência preenchendo pequenas fraturas .

Segundo Krauskopf (1970), a alteração dos minerais de Mo coloca em solução os íons molibdato, forma sob a qual este elemento é absorvido pela planta.

ESTUDOS DE CORRELAÇÃo Os diagramas de dispersão permitem verificar se as variáveis empregadas são espacialmente associadas, além de possibilitar a visualização do conjunto de dados na forma de histogramas bidimensionais (Lepeltier 1969).

Neste trabalho os diagramas de dispersão foram utilizados em associação com o coeficiente de correlação que é

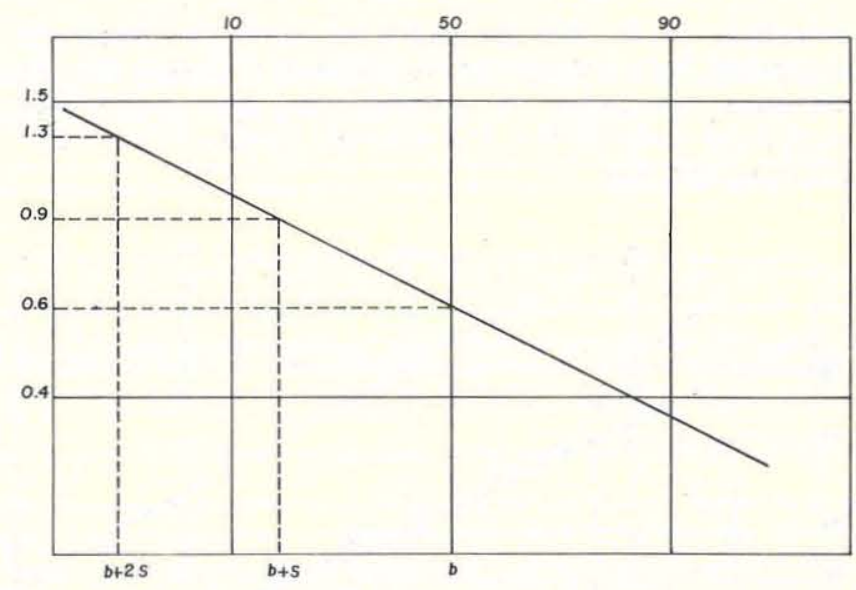

Figura 12 - Curva de freqüencia acumulada dos teores de Mo em amostras de S. lentiscifolius da área do Complexo Granítico Lavras (intervalos aritméticos)

a medida de ajustamento dos dados à curva de regressão. Neste caso, optou-se pelo Coeficiente de Spearmann, que, ao contrário do Coeficiente de Pearson, pode ser usado em quaisquer que sejam as distribuições das populaçöes comparadas (Brooks 1972). O nível de significância adotado é o de 0,05 e os valores significativos do Coeficiente de Spearmann $\left(r_{s}\right)$ estão representados sob a forma de matriz na figura 14.

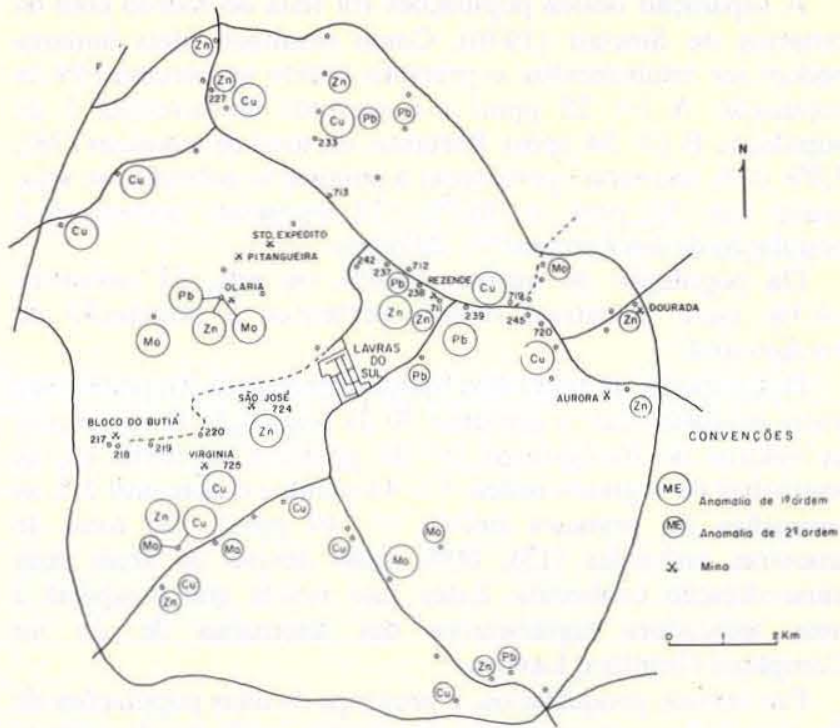

Figura 13 - Mapa de anomalias biogeoquímicas na área do Complexo Granítico Lavras

\section{RELAÇÃO DOS ELEMENTOS ENTRE SI NA}

PLANTA Das correlações entre os pares de elementos estudados na espécie considerada, mostram-se mass significativas as seguintes:

$\mathrm{Pb} \times \mathrm{Fe}-\mathrm{O}$ antagonismo observado entre o $\mathrm{Pb}$ e o Fe indica que o primeiro, quando mais disponível à planta, interfere na absorçâo do Fe pela mesma; segundo Kabata-Pendias \& Pendias (1984), os cátions metálicos competem com o $\mathrm{Fe}^{2+}$ juntamente com o $\mathrm{Fe}$, indica como fonte provedora a pirita onde de fato o $\mathrm{Cu}$ é mais enriquecido, principalmente no pertita granito (Fig. 15).

$\mathrm{Zn}$ x Mn - Também surpreende o sinergismo existente entre geoquímicos, pode-se supor que o $\mathrm{Cu}$, ao ser absorvido 


\begin{tabular}{|c|c|c|c|c|c|c|c|c|c|c|c|}
\hline & $\mathrm{Cu}$ & $\mathrm{Pb}$ & $2 \mathrm{n}$ & Mo & $\mathrm{Rb}$ & ca & $\mathrm{Fe}$ & Mg & $\mathrm{Mn}$ & $\mathrm{Na}$ & $\mathrm{K}$ \\
\hline $\mathrm{Cu}$ & 1 & $+0,44$ & $-0,40$ & & & & $+0,33$ & & & & \\
\hline $\mathrm{Pb}$ & & 1 & & & & & $-0,36$ & & & & \\
\hline $\mathrm{zn}$ & & & 1 & & & & & & $+0,62$ & & \\
\hline Mo & & & & 1 & & & & & & & \\
\hline Rb & & & & & 1 & & & & & & $+0,84$ \\
\hline $\mathrm{Ca}$ & & & & & & 1 & & & & & \\
\hline $\mathrm{Fe}$ & & & & & & & 1 & & $+0,30$ & & \\
\hline Mg & & & & & & & & 1 & & & \\
\hline $\mathrm{Mn}$ & & & & & & & & & 1 & & \\
\hline $\mathrm{Na}$ & & & & & & & & & & 1 & $+0,38$ \\
\hline K & & & & & & & & & & & 1 \\
\hline
\end{tabular}

Figura 14 - Coeficiente de correlação ordinal dos elementos entre si em $\mathrm{S}$. lentiscifolius, nível de significância $=0,05, \mathrm{v}_{\mathrm{s}}$ crit. $=0,27$

juntamente com o $\mathrm{Fe}$, indica como fonte provedora a pirita onde de fato o $\mathrm{Cu}$ é mais enriquecido, principalmente no pertita granito (Fig. 15).

Zn x Mn - Também surpreende o sinergismo existente entre estes elementos já que tal fenômeno na planta, de acordo com Kabata-Pendias \& Pendias (1984), não é comum entre elementos-traços; contudo, argumentam que muitas das relaçöes que ocorrem no meio que circunda as raízes, e que afetam a absorção, não devem estar associadas às atividades metabólicas, sendo no entanto os dois processos dificilmente separáveis. Além disso, a forte capacidade de sorção dos óxidos de $\mathrm{Mn}$ de outros cátions metálicos é um fator que predispōe, em muito, a disponibilidade destes para as plantas (Fig. 16).

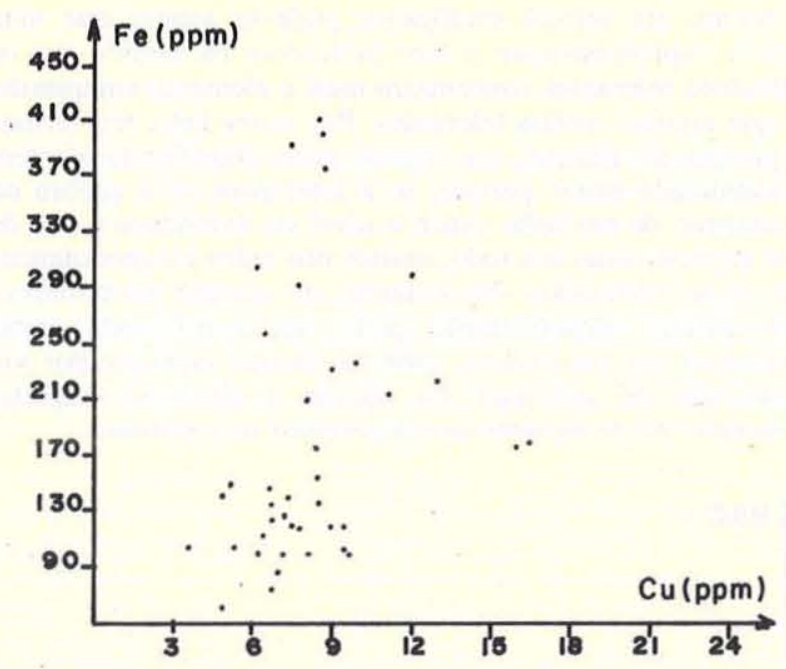

Figura 15 - Diagrama de dispersâo entre o Cu e o Fe em $\mathrm{S}$. lentiscifolius $(\mathrm{n}=38)$

$\mathrm{Ca}, \mathrm{Mg}, \mathrm{K} \times \mathrm{Cu}, \mathrm{Pb}$ e $\mathrm{Zn}-\mathrm{A}$ ausência de uma correlaçāo negativa significativa entre os macronutrientes e os elementos metálicos, principalmente entre o $\mathrm{Ca}$ e o $\mathrm{Cu}, \mathrm{Pb}$ ou $\mathrm{Zn}$, cuja função do primeiro é proteger a integridade das paredes celulares contra a absorção excessiva dos elementos tóxicos, sugere que esta espécie tem reaçōes geneticamente específicas e muito variáveis, as quais podem ocorrer tanto no interior das células como na superfície das membranas celulares ou, ainda, a nível de raízes. Ou seja, a absorção dos elementos metálicos não interfere na absorção dos macronutrientes e vice-versa.

$\mathrm{Na} \times \mathrm{K}$ e $\mathrm{Fe} \times \mathrm{Mn}-\mathrm{O}$ fato de estas associações geoquímicas no substrato também serem refletidas na planta é indicativo de uma absorção passiva por parte da mesma, sem acúmulo ou rejeição de qualquer um desses elementos em particular (Brooks \& Yang 1984). É provável também que, no caso do $\mathrm{Fe}$ e do $\mathrm{Mn}$, estes estejam mais fortemente ligados a compostos orgânicos à semelhança do $\mathrm{Zn}$, que é quase inteiramente ligado a esses compostos (Van Goor \& Wiersma 1976 apud Kabata-Pendias \& Pendias 1984).

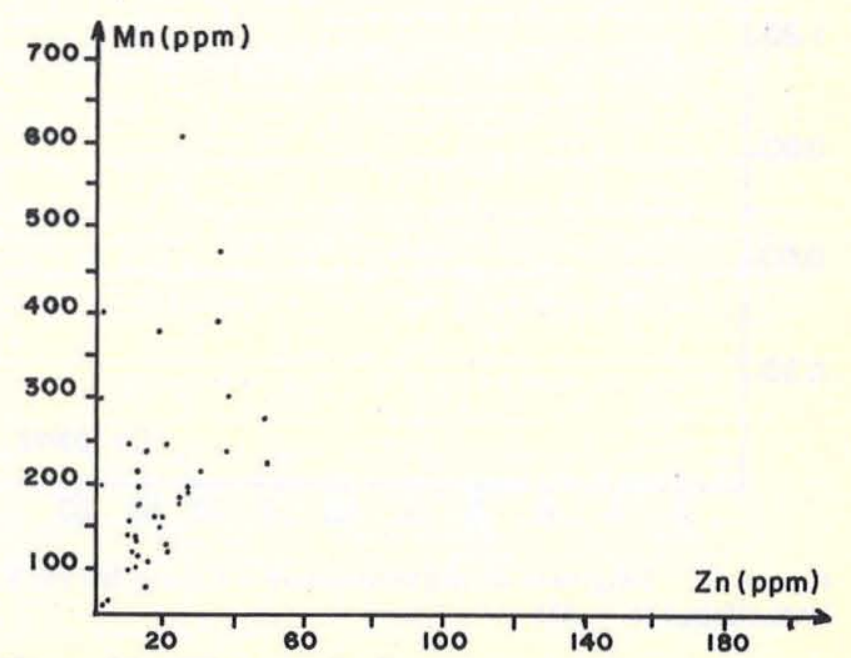

Figura 16 - Diagrama de dispersão entre o Zn e o $\mathrm{Mn}$ em $\mathrm{S}$. lentiscifolius $(\mathrm{n}=38)$

$\mathrm{Cu} \times \mathrm{Zn}$ - A relação existente entre o $\mathrm{Cu}$ e o $\mathrm{Zn}$ em $S$. lentiscifolius indica que ambos, embora sejam absorvidos por processos diferentes, são tolerados pela espécie em concentrações semelhantes, o que confere a esta planta um caráter de multitolerância a teores elevados de elementos metálicos, fenômeno também constatado por Gregory \& Bradshaw (1965) em gramíneas e por Porto (1981) para a espécie acima citada (Fig. 17).

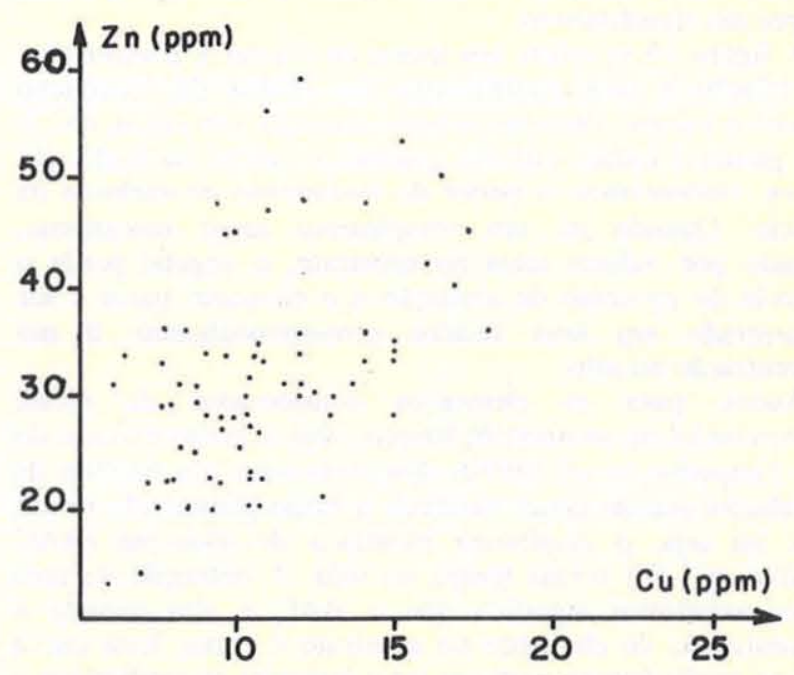

Figura 17 - Diagrama de dispersão entre o Cu e o Zn em S. lentiscifolius $(\mathrm{n}=75)$

$\mathrm{Cu} \times$ Mo - A relação negativa existente entre estes dois elementos (Fig. 18) reforça o antagonismo existente entre ambos ao serem absorvidos pelo vegetal. Este fenômeno impede que o $\mathrm{Cu}$ e o Mo sejam absorvidos pela planta em quantidades semelhantes. Gartell (1981, apud Kabata-Pendias \& Pendias op. cit.) argumenta que os fatores que aumentam a 
disponibilidade do Mo, geralmente têm um efeito inibidor na absorção do $\mathrm{Cu}$ e que a barreira fisiológica do vegetal na absorção do Mo é muito menos efetiva do que aquela do $\mathrm{Cu}$.

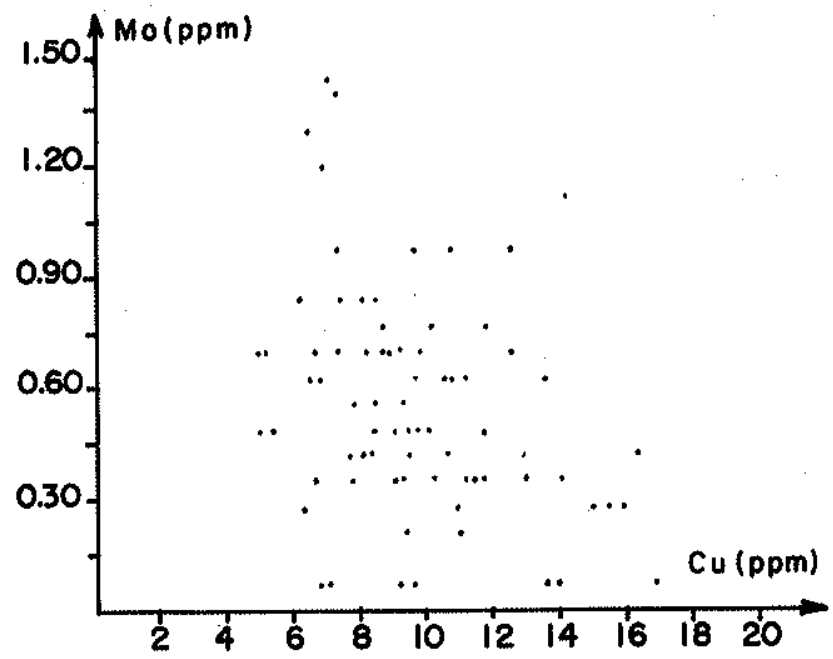

Figura 18 - Diagrama de dispersão entre o Cu e o Mo em $\mathrm{S}$. lentiscifolius $(\mathrm{n}=75)$

\section{RELAÇÃO dOS ELEMENTOS ENTRE A PLANTA E} ROCHA Segundo Brooks (1983), o sucesso do emprego do método biogeoquímico está na dependência de que o elemento pesquisado seja absorvido de modo proporcional a sua concentração no solo. No entanto, quando se trata com elementos essenciais, uma correlação entre as variáveis

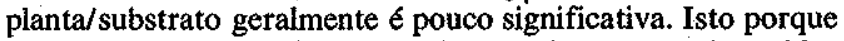
esses elementos, considerados micronutrientes, săo absorvidos pela planta de maneira controlada, ou seja, esta tende a manter em seus tecidos uma concentração constante, independente dos teores destes no meio. É devido a tal mecanismo que correlaçöes diretas entre teores na planta e teores no solo nem sempre são significativas.

A figura 19 se refere aos teores de $\mathrm{Cu}$ em S. lentiscifolius em relação a seus equivalentes nas rochas do Complexo Granítico Lavras. Percebe-se neste caso que a absorção do $\mathrm{Cu}$ pela planta é muito variável quando os teores na rocha sáo baixos, evidenciando o poder do mecanismo de exclusão da espécie. Quando há um rompimento nesse mecanismo, causado por valores altos no substrato, o vegetal perde o controle do processo de absorção e o elemento passa a ser concentrado em seus tecidos proporcionalmente à sua concentração no solo.

Assim, para os elementos considerados de difícil interpretação em prospecção biogeoquímica, como é o caso do $\mathrm{Cu}$, Timperley et al. (1970) desenvolveram um método de correlação usando como variáveis a razão planta/solo versus solo, ou seja, o coeficiente biologico de absorção (BAC Brooks op. cit.) versus teores no solo. A obtenção de uma curva assintótica significa que o BAC é alto quando a concentração do elemento no substrato é baixa. Esta curva declina gradualmente para um valor limitante na medida que a concentração no meio aumenta, ou seja, o BAC decresce proporcionalmente ao aumento da concentração no substrato no sentido de preservar a constante $k$, que $e$ igual à concentração do elemento na planta ao nível de sua exigência fisiologica máxima.

A correlação dessas variáveis na área estudada (Fig. 20), revela para a constante $k$ um valor de $12 \mathrm{ppm}$ de $\mathrm{Cu}$. Observa-se que esta constante, obtida pela multiplicação do valor médio de $\mathrm{X}$ (teores de $\mathrm{Cu}$ na planta) pelo valor médio de Y (razão planta/rocha), equivale àquele valor acima do qual a planta passa a retratar as anomalias geoquímicas.

Em vista disso, pode-se deduzir que $S$. lentiscifolius desenvolve graus de tolerância a nfvel de indivfduos, podendo, portanto, ser enquadrada na categoria de "cuprorresistente", definida por Brooks (1983) como sendo uma espécie onipresente que resiste tanto a concentrações fracas como médias ou fortes de $\mathrm{Cu}$ no substrato.

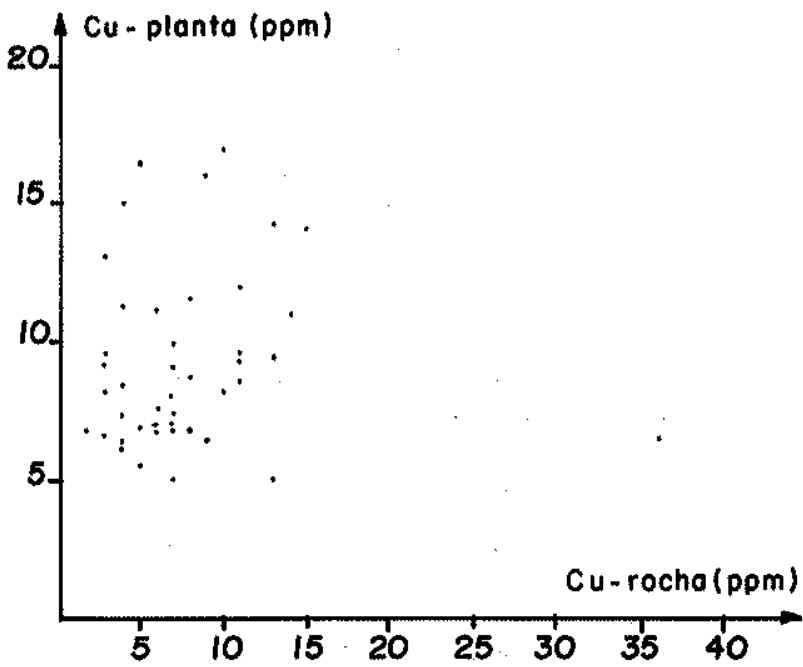

Figura 19 - Diagrama de dispersão entre o Cu em S. lentiscifolius $e$ seus equivalentes nas rochas do Complexo Grantitico Lavras $(\mathrm{n}=43)$

Assim, em termos ecologicos, pode-se atestar que uma espécie cuprorresistente é uma indicadora na medida que os indíviduos tolerantes concentram mais o elemento em questão do que aqueles menos tolerantes. Por outro lado, em termos de prospecção mineral, um vegetal assim classificado não tem aplicabilidade maior porque, se a tolerância ou a quebra no mecanismo de exclusão existe a nivel de indivíduos e não de uma espécie como um todo, muitos dos halos biogeoquímicos não serão retratados. No entanto, no sentido geobotânico, uma planta cuprotolerante pode ser considerada como indicadora por predominar sobre as demais espécies, por sua capacidade de restringir ou tolerar a absorção daqueles elementos que se encontram enriquecidos no substrato.

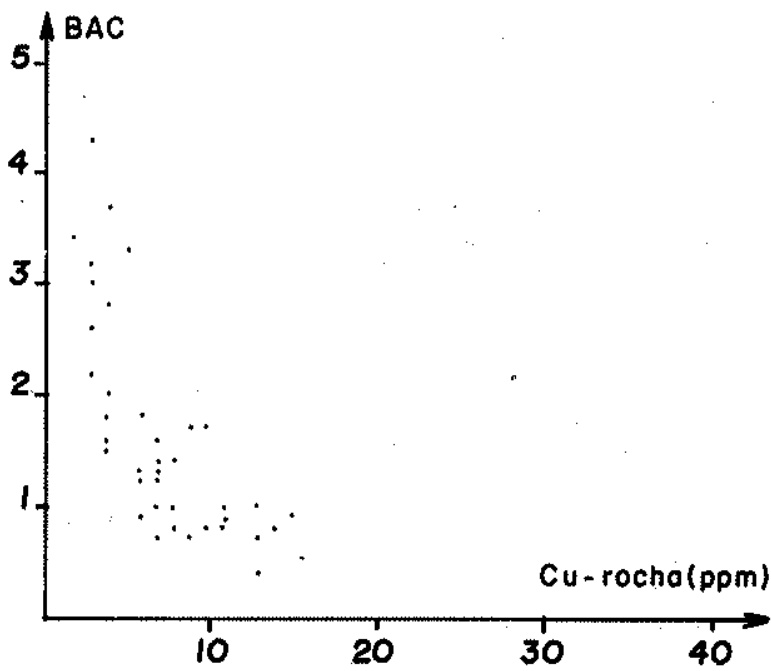

Figura 20 - Coeficiente biologico de absorção (BAC) (Brooks 1983) do $\mathrm{Cu}$ em relação aos teores equivalentes nas rochas do Complexo Grantitico Lavra $(\mathrm{n}=43)$ 
No caso do $\mathrm{Zn}$, embora este elemento também seja essencial à planta. observa-se pela figura 21 , um leve mas progressivo aumento de absorção pela espécie estudada, na medida que os teores na rocha são mais elevados, indicando que a absorção deste elemento é proporcional ao aumento de sua disponibilidade. A maior tolerância que $S$. lentiscifolius apresenta em relação ao $\mathrm{Zn}$ indica ser este menos tóxico que o $\mathrm{Cu}$. Ainda, comparando-se as figuras 19 e 21, percebe-se que o padrão de absorção de $\mathrm{Cu}$ difere daquele do $\mathrm{Zn}$, fato também constatado por Antonovics et al. (1971).

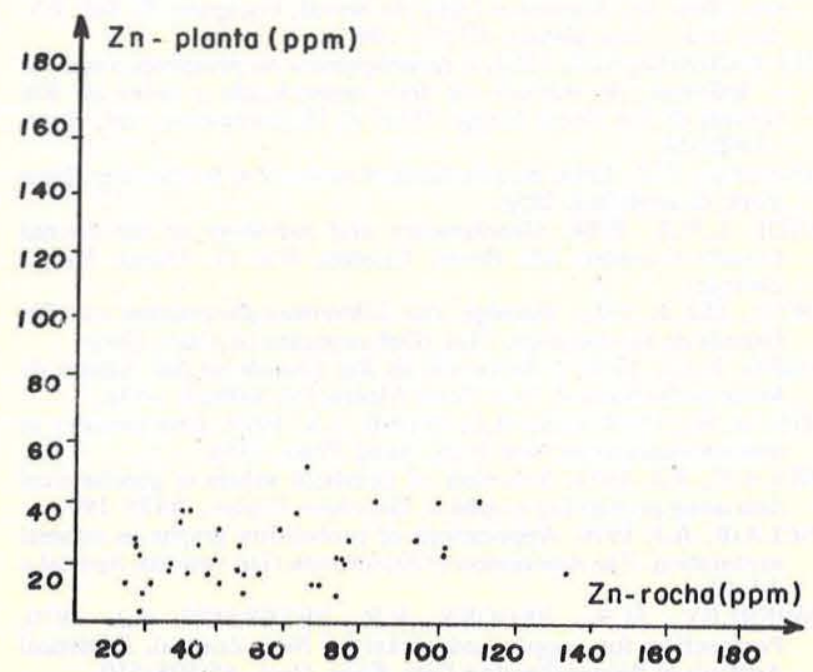

Figura 21 - Diagrama de dispersäo entre os teores de Zn em $\mathrm{S}$. lentiscifolius $e$ seus equivalentes nas rochas do Complexo Granítico Lavras $(\mathrm{n}=43$ )

Cabe aqui ressaltar que as relaçöes obtidas entre os teores dos elementos-traço na planta e seus equivalentes no meio geralmente são obtidas a partir dos valores de solo. É possível, portanto, que as correlações pouco ou nada significativas observadas nas figuras 19 e 21 sejam devidas não só aos processos fisiológicos do vegetal como também à menor disponibilidade dos elementos, já que seus valores no vegetal, no caso deste trabalho, são comparados com os teores na rocha. Sabe-se que os vegetais absorvem mais prontamente aqueles cátions que se encontram móveis na solução do solo ou os adsorvidos nos argilo-minerais, ou ainda absorvidos pelos compostos orgânicos. Portanto, os elementos mais firmemente retidos na rede cristalina dos minerais são praticamente não disponíveis à planta. Contudo, a açâo das raízes (aliada à ação dos microrganismos que circundam o meio radicular) é um fenômeno que contribui para a solubilização dos compostos inorgânicos relativamente insóluveis, nâo devendo ser ignorada nos processos de alteração das rochas.

Para o chumbo, a total ausência de correlação entre os teores no vegetal e os na rocha pode ser atribuída aos seguintes fatores:

- A absorção do chumbo pelas plantas é feita de modo passivo, sendo que somente 3\% do elemento absorvido pelas raízes é translocado para as partes aéreas (Zimdahl 1975 apud Kabata-Pendias \& Pendias 1984):

- Estudos feitos têm demonstrado que apenas de 0,03 a $0,05 \%$ do chumbo existente no solo é disponível à planta.

- A toxicidade do chumbo, similar à do cobre, faz os vegetais acionarem seu mecanismo de exclusão, .que, segundo Antonovics et al. (1971) é muito semelhante tanto para o chumbo como para o cobre.

A interação dos fatores acima, aliada ao fato de que os teores de chumbo da espécie sejam comparados com os da rocha, justifica a ausência de uma correlação entre a concentração deste elemento na espécie e os teores das rochas.

Em relaçāo ao Mo, não foi possível confrontar os dados pois a quase totalidade dos valores disponíveis das rochas se revelou abaixo do limite de deteç̧ão do mesmo em termos analíticos.

ASPECTOS CONCLUSIVOS A presença de elementos metálicos nas plantas indica a presença destes no substrato (Malyuga 1964), não existindo, no entanto, uma dependência direta entre o conteúdo dos elementos químicos na forma disponível, isto é, assimilável pelo vegetal, e seu conteúdo total nos solos. Daí a ausência de uma relação mais direta entre essas duas variáveis, conforme observado este trabalho e também em outros registrados na literatura biogeoquímica.

- Como se expôs nos perfis biogeoquímicos e considerando-se que, das 13 amostras anômalas em zinco, $60 \%$ estão relacionadas com ocorrências conhecidas, pode-se atestar que este elemento se revela como o melhor indicador biogeoquímico das mineralizaçōes polimetálicas do Complexo Granítico Lavras, principalmente quando sobre o granito central, onde os sulfetos de $\mathrm{Zn}, \mathrm{Cu}$ e $\mathrm{Pb}$, contidos em veios de quartzo, ou disseminados em áreas hidrotermalmente alteradas, estão associados à mineralização aurífera.

- Em relação ao $\mathrm{Cu}$ e $\mathrm{Pb}$, apenas $18 \%$ das 16 amostras anômalas do primeiro e $30 \%$ das 10 do segundo coincidem com áreas de ocorrência de minério, indicando que estes elementos têm uma menor aplicabilidade em prospecção biogeoquímica para a área estudada, se comparados ao Zn e ao Mo. A capacidade da planta regular forteménte a absorção dos elementos essenciais e/ou muito tóxicos impede que, neste caso, os halos biogeoquímicos tenham um significado maior. Cabe ressaltar no entanto que a maior parte das amostras anômalas em cobre ocorre no pertita granito, em que a mineralização aurífera é constituída principalmente por pirita disseminada em rocha com granulação fina.

- O padrão de distribuição do molibdênio revela que das oito amostras anômalas $50 \%$ coincidem geograficamente com áreas já explotadas. Este fato parece indicar uma fonte muito próxima de Mo para a espécie, podendo ser o mesmo proveniente de mineralizações sulfetadas das ocorrências conhecidas.

- Em relação ao aspecto fitomorfológico da espécie considerada, observou-se que as amostras coletadas particularmente na Mina São José (E de Lavras do Sul) e Mina Rezende (W da cidade), em que o teor de zinco nas cinzas se revelou significativamente alto, os exemplares apresentam-se fragéis, pouco vigorosos, com ramos secundários mais finos e providos de poucas folhas; estas têm uma coloraçāo verde-pálida em vez da verde-prateada, típica das aroeirinhas. Tais características demonstram que esta planta, mesmo sendo uma tolerante, é afetada por mudanças bruscas no conteúdo mineral do solo. Em alguns locais da área, mais precisamente a N-NE e a SE, constatou-se também que a freqüência de $S$. lentiscifolius diminui sensivelmente. Este fato sugere que dentro da espécie há espécimens que desenvolvem uma maior resistência às condiçōes adversas. Esta diferenciação revela que a aroeirinha, mesmo formando um ecótipo distinto dentro de uma área homogênea, em termos climáticos e geomorfológicos, sofre adaptações em função das modificações do conteúdo mineral do solo. Segundo Epstein (1975), o êxito na adaptação implica que o organismo use o meio de maneira vantajosa para que possa suprir suas necessidades fisiológicas e contornar as características que lhe são impróprias.

- No que se refere aos critérios estatísticos empregados para a determinação das anomalias biogeoquímicas, procurou-se estabelecer, por meio de diferentes técnicas, parâmetros de avaliação próprios para cada tipo de população, lembrando, no entanto, o postulado de Rose et al. (1979) de que a 
análise matemática pura não substitui a interpretação subjetiva.

Agradecimentos
São aqui expressos agradecimentos aos
Professores R. Cunha e L.V.S. Nardi, pelas críticas, sugestões e coleta de parte das amostras; à Finep, pelo auxílio financeiro; e ao CNPq, pela concessão de bolsa de pesquisa.

\section{REFERÊNCIAS BIBLIOGRÁFICAS}

ANTONOVICS, J.; BRADSHAW, A.D.; TURNER, R.G, 1971. Heavy metal tolerance in the Plants. In: CRAGG, J.B. ed. Advances in ecological research, 7:1-83, Academic Press, London.

BEUS, A.A. \& GRIGORIAN, S.V. 1977. Geochemical exploration: methods for mineral deposits. Applied Pub. Illinois, USA, 287p.

BROOKS, R.R. 1972. Geobotany and Biogeochemistry in mineral exploration. Harper \& Row, New York, 290p.

BROOKS, R.R 1979. Indicator plants for mineral prospecting - A critique. J. Geochem. Explor., 12(1):68-78.

BROOKS, R.R. 1983. Biological methods of prospecting for minerals. John Wiley \& Sons, New York, 322p.

BROOKS, R.R. \& YANG, X. 1984. Elemental levels and relationships in the endemic serpentine flora of the Great Dyke, Zimbabwe, and their significance as controlling factors for the flora. Taxon, 33(3):392-399.

CONNOR, J.J. \& SHACKLETTE, H.T. 1975. Background geochemistry of some rocks, soils, plants and vegetables in the Counterminous United States. U.S. Geol. Surv. Washington, DC. 168p. (Prof paper, 574-F).

CHUKHROV, F.V.; CHURIKOV, V.S.; ERMILOVA, L.P.; KALENTCHUK, B.E. 1979. Background levels for copper and zinc in common plants from various regions of the Soviet Union. J. Geochem. Explor., 12(1):79-86.

EPSTEIN, E. 1975. Nutrição mineral das plantas. Princípios $e$ perspectivas. São Paulo, EDUSP. 341p.

GARRET, R.G. 1984. Thresholds and anomaly interpretation. $J$. Geochem. Explor., 21(1-3):137-142.

GREGORY, R.P.G. \& BRADSHAW, A.D. 1965. Heavy metal tolerance in populations of Agrostis tenuis Sibth. and other grasses. New Phytol., 64:131-143.

HAWKES, H.E. \& WEEB, J.S. 1962. Geochemistry in mineral exploration. Harper \& Row Pub., New York, 415p.

KABATA-PENDIAS, A. \& PENDIAS, H. 1984. Trace elements in soils and plants. Florida, CRC Press. $315 \mathrm{p}$.

KRAUSKOPF, K.B. 1970. Geochemical of micronutrients. In: MORTVEDT, J.J.; GIORDANO, P.M.; LINDSAY. W.L. Micronutrients in agriculture. Soil. Science Society of America. $630 \mathrm{p}$.
LEPELTIER, C. 1969. A simplified statistical treatment of geochemical data by graphical representation. Econ. Geol., 64:538-550.

LIMA E CUNHA, M.C. 1980. Prospeç̧ão biogeoquímica para cobre em Cerro dos Martins e Mina do Seival, Caçapava do Sul, RS. Acta Gelo. Leopoldensia, 4(8):95-108.

LIMA E CUNHA, M.C. 1982. A biogeoqut́mica na prospeç̧ão mineral - Aplicação do método em área mineralizada a cobre do Rio Grande do Sul. Porto Alegre. (Tese de Doutoramento, Inst. Geoc. - UFRGS).

MALYUGA, D.P. 1964. Biogeochemical methods of prospecting. New York, Consult Bur. 205p.

NARDI, L.V.S. 1984. Geochemistry and petrology of the Lavras Granite Complex, RS, Brasil. London. (Ph. D. Thesis, King's College).

PORTO, M.L.J. 1981. Beiträge Zur Schwermetallvegetation von Rio Grande do Sul-Brasilien. Ulm, (Doktorgrades Dr,Univ. Ulm).

RAMBO, B.S.J. 1956. A fisionomia do Rio Grande do Sul. Ensaio de Monografia Natural. 2 ed. Porto Alegre, Ed. Selbach. 443p.

ROSE, A.W.; HAWKES, H.E; WEBB, J.S. 1979. Geochemistry in mineral exploration. New York, Acad. Press. 675p.

SINCLAIR, A.J. 1974. Selection of threshold values in geochemical data using probability graphs. J. Geochem. Explor., 3:129-149.

SINCLAIR, A.J. 1976. Applications of probability graphs in mineral exploration. The Association of Exploration Geochemists, Special v 4:1-95.

TIMPERLEY, M.H.; BROOKS, R.R; PETERSON, P.J. 1970. Prospecting for copper and nickel in New Zealand. Statistical Analysis of Biogeochemical Data. Econ. Geol., 65:505-510.

WARREN, H.V.; DELAVAULT, R.E.; IRISH, R. 1952. Preliminary studies on the biogeochemistry of iron and manganese. Econ. Geol., 47(2):131-145.

MANUSCRITO 540

Recebido em 18 de maio de 1988 Revisão aceita em 21 de setembro de 1988 